\title{
Effect of ammonia intoxication on cerebral blood flow, its autoregulation and responsiveness to carbon dioxide and papaverine
}

\author{
ADAM CHODOBSKI,* JOANNA SZMYDYNGER-CHODOBSKA, $\dagger$ \\ KRYSTYNA SKOLASIŃSKA* \\ From the Microcirculation Research Unit, ${ }^{*}$ and Department of Physiology, $\dagger$ Institute of Physiological \\ Sciences, School of Medicine, Warsaw, Poland
}

SUMMARY Cerebral blood flow (CBF) was measured in anaesthetised cats with ${ }^{133}$ Xe clearance method under normal conditions and with hyperammonaemia. Elevation of blood ammonia concentration by an intravenous infusion of ammonium acetate caused an increase in CBF and a parallel decrease in cerebrovascular resistance (CVR). These parameters reached, however, plateau at an arterial blood ammonia level exceeding $500 \mu \mathrm{mol} / 1$. Cerebrovascular reactivity to $\mathrm{CO}_{2}$ diminished following elevation of blood ammonia concentration and at arterial blood ammonia level exceeding $500 \mu \mathrm{mol} / 1$ it was virtually abolished. In contrast, hyperammonaemia influenced neither cerebrovascular responsiveness to papaverine nor autoregulatory properties of the cerebral circulation. It is concluded, therefore, that hyperammonaemia exerts some dilatatory effect on cerebral vessels and severely impairs chemical regulation of CBF but does not elicit cerebral vasomotor paralysis.

A pathogenic role of ammonia in hepatic encephalopathy and coma had already been recognised at the end of the last century. ${ }^{1}$ However, the mechanisms by which hyperammonaemia affects the central nervous system are not clear. Especially, the effect of ammonia on regulation of the cerebral blood flow (CBF) still remains to be elucidated.

In 1976 Chandler and $\mathrm{Kindt}^{2}$ demonstrated significant elevation of intracranial pressure (ICP) in patients suffering from hepatic encephalopathy of different aetiologies. An increase in ICP by $200-300 \%$ of control values has also been found in rhesus monkeys during hyperammonaemia elicited by intravenous infusion of ammonium acetate. ${ }^{3}$ Altenau and $\mathrm{Kindt}^{4}$ using the same experimental model have found that ammonia intoxication causes an increase in CBF and impairs cerebrovascular reactivity to $\mathrm{CO}_{2}$ and autoregulatory properties of cerebral circulation. Basing on these results, these authors have postulated that ammonia intoxication brings about the cerebral vasomotor paralysis leading to an increase in intra-

Address for reprint requests: Adam Chodobski, Microcirculation Research Unit, Institute of Physiological Sciences, School of Medicine, Krakowskie Przedmieście 26/28, 00-927 Warsaw, Poland.

Received 23 November 1984 and in revised form 9 July 1985. Accepted 13 July 1985 cranial blood volume, which in turn would produce an elevation of ICP.

The present study was undertaken to evaluate the effect of elevation of blood ammonia concentration on $\mathrm{CBF}$ and its responsiveness to $\mathrm{CO}_{2}$. Furthermore, cerebrovascular reactivity to papaverine, the agent known to affect cerebral vessels in a manner different from carbon dioxide, as well as autoregulatory properties of cerebral circulation were examined under normal conditions and with hyperammonaemia in order to elucidate whether an elevation of blood ammonia concentration may result in the vasomotor paralysis of the cerebral vessels.

\section{Materials and methods}

The experiments were carried out on 82 cats of either sex weighing between 2.4 and $3.8 \mathrm{~kg}$. Anaesthesia was induced with pentobarbital sodium (Nembutal-Abbott) injected intraperitoneally in a dose of $20 \mathrm{mg} / \mathrm{kg}$ and maintained with intravenous alpha-chloralose $(60 \mathrm{mg} / \mathrm{kg})$. A tracheostomy was performed and catheters inserted into the left femoral artery and vein for measurement of mean arterial blood pressure (MABP), collection of arterial blood samples and intravenous administration of drugs and solutions. In the experiments, in which autoregulation of CBF was examined the right femoral artery was additionally cannulated for withdrawal of blood to produce controlled hypotension. The 
right cephalic vein was cannulated to induce hyperammonaemia by infusion of ammonium acetate. In order to measure CBF a thin catheter was inserted centripetally through the right lingual artery, so that its tip was located near the external carotid artery. The cat was subsequently mounted in a stereotaxic apparatus. The scalp and temporal muscles were detached to provide an access to frontal, parietal and temporal areas of the calvarium. A 20-gauge needle was introduced into the cisterna magna for a continuous monitoring of ICP. Gallamine triethiodide (TricuranGermed) was administered intravenously in a dose of 3-4 $\mathrm{mg} / \mathrm{kg}$ to cause muscle relaxation and artificial ventilation was maintained throughout the course of the experiment. The respiratory rate and volume were adjusted to achieve arterial carbon dioxide tension $\left(\mathrm{PaCO}_{2}\right)$ close to $28 \mathrm{~mm} \mathrm{Hg}$. This $\mathrm{PaCO}_{2}$ level was maintained throughout the experiment except when it was deliberately changed. In the experiments, in which autoregulation of CBF was evaluated arterial oxygen tension $\left(\mathrm{PaO}_{2}\right)$ was maintained within the range of $140-160 \mathrm{~mm} \mathrm{Hg}$ by adjusting the inspiratory oxygen content. Rectal temperature was kept at $37-38^{\circ} \mathrm{C}$ by external warming with heating pad.

Four series of experiments were performed.

Series I Effect of hyperammonaemia on basal cerebral blood flow and cerebrovascular reactivity to $\mathrm{CO}_{2}$

This series of experiments was performed on 14 cats. Measurements of CBF under conditions of normal blood ammonia levels were started one hour after completion of the surgical procedure. Subsequently, the infusion of ammonium acetate into the cephalic vein was started. In order to cover a wide range of blood ammonia concentration ammonium acetate was infused at the following rates: $0 \cdot 39,0.55$, $0.65,0.86,1.08,1.30,1 \cdot 74,1.95,2 \cdot 16$ and $2.60 \mathrm{mmol} / \mathrm{kg} / \mathrm{h}$. In each experiment 2-4 different rates of infusion were used. The blood samples to determine arterial blood ammonia concentration were taken $\mathbf{4 0}$ minutes after the onset of each of the infusion rates. This was followed by measurements of $\mathrm{CBF}$.

CBF values to be subjected to further analysis were corrected for the difference between $\mathrm{PaCO}_{2}$ actually found at the moment of CBF measurement and the level of $28 \mathrm{~mm} \mathrm{Hg}$, which according to Fink and Schoolman ${ }^{5}$ corresponds to a normocapnic level in the cat. Corrected values of $\mathrm{CBF}$ (cCBF) were obtained using the following equation:

$$
\mathrm{cCBF}=\mathrm{CBF}+\mathrm{CI}\left(28-\mathrm{PaCO}_{2}\right) \mathrm{ml} / \mathrm{min} / 100 \mathrm{~g}
$$

where $\mathrm{CI}$ is an index of the chemical regulation of CBF (see below). Additionally, the cerebrovascular resistance (CVR) was calculated as a ratio of the cerebral perfusion pressure (CPP) to cCBF. CPP was defined as a difference between MABP and mean ICP.

Cerebrovascular reactivity to $\mathrm{CO}_{2}$ with and without hyperammonaemia was determined on the basis of two successive CBF measurements performed either under normal or hypercapnic conditions. Hypercapnia was achieved by an elevation of $\mathrm{CO}_{2}$ content in the inspiratory air resulting in $\mathrm{PaCO}_{2}$ of $43.6 \pm 0.8 \mathrm{~mm} \mathrm{Hg}$ (range $34-55 \mathrm{~mm} \mathrm{Hg}$ ). CBF was measured 5 minutes after induction of hypercapnia. To assess the cerebrovascular reactivity to $\mathrm{CO}_{2}$ an index of chemical regulation of CBF (CI) was applied. ${ }^{6}$ This index was calculated using the following equation:

$$
\mathrm{CI}=\frac{\Delta \mathrm{CBF}}{\Delta \mathrm{PaCO}_{2}}(\mathrm{ml} / \mathrm{min} / 100 \mathrm{~g} / \mathrm{mm} \mathrm{Hg})
$$

where $\triangle \mathrm{CBF}$ is a measure of $\mathrm{CBF}$ response to the increment in $\mathrm{PaCO}_{2}\left(\triangle \mathrm{PaCO}_{2}\right)$ above the level of normocapnia established in particular experiments.

Series II Examination of relationship between $\mathrm{PaCO}_{2}$ and cerebral blood flow under conditions of normal blood ammonia and hyperammonaemia

This series of experiments, performed on 20 cats, was designed to determine the relationship between $\mathrm{PaCO}_{2}$ and CBF under conditions of normal blood ammonia and after elevation of arterial blood ammonia concentration to above $500 \mu \mathrm{mol} / \mathrm{l}$, that is to a level at which severe impairment of the cerebrovascular reactivity to $\mathrm{CO}_{2}$ was observed (series I). CBF was measured at various levels of $\mathrm{PaCO}_{2}$ within the ranges of $22.0-58.5 \mathrm{~mm} \mathrm{Hg}$ and $23.0-53.5 \mathrm{~mm} \mathrm{Hg}$ under normal conditions and with hyperammonaemia, respectively. Measurements of CBF under conditions of normal blood ammonia levels were started one hour after completion of the surgical procedure. In each experiment 2 or 3 normal blood ammonia CBF measurements at various levels of $\mathrm{PaCO}_{2}$ were followed by infusion of ammonium acetate into cephalic vein at the rate of $2 \cdot 16 \mathrm{mmol} / \mathrm{kg} / \mathrm{h}$. The blood sample to determine arterial blood ammonia concentration was taken 40 minutes after the onset of ammonium acetate infusion. This was followed by 2 or $3 \mathrm{CBF}$ measurements at various levels of $\mathrm{PaCO}_{2}$, similarly as under conditions of normal blood ammonia.

The data obtained in this series of experiments were subjected to the linear regression analysis. Coefficients of the slope of regression lines, corresponding to $\mathrm{CI}$ in series I, were used to correct CBF measurements in series III and IV and to present them as normalised values corresponding to $\mathrm{PaCO}_{2}$ of $28 \mathrm{~mm} \mathrm{Hg}$.

Series III Effect of hyperammonaemia on cerebrovascular reactivity to papaverine

This series of experiments was performed on 14 cats. Cerebrovascular reactivity to papaverine under conditions of normal blood ammonia was evaluated one hour after completion of the surgical procedure. Subsequently, an intravenous infusion of ammonium acetate was started at the same rate as in series II. The blood sample to determine arterial blood ammonia concentration was taken 40 minutes after the onset of ammonium acetate infusion. This was followed by determination of the cerebrovascular reactivity to papaverine under conditions of hyperammonaemia. Cerebrovascular responsiveness to papaverine was determined on the basis of CBF measurements performed before and after administration of papaverine and defined as a percentage increase in the base-line cCBF. CBF values were corrected for the difference between $\mathrm{PaCO}_{2}$ actually found at the moment of CBF measurement and the level of $28 \mathrm{~mm} \mathrm{Hg}$, basing on the data obtained in series II. Papaverine hydrochloride (Karlspharma) was infused intravenously at the rate of $1 \mathrm{mg} / \mathrm{kg} / \mathrm{min}$ and CBF measured 5 minutes after the onset of papaverine infusion. 
Series IV Autoregulation of cerebral blood flow under normal conditions and with hyperammonaemia

This series of experiments was performed on two groups of animals. In the first group autoregulation of CBF was examined under conditions of normal blood ammonia. The animals were subjected either to reduction (10 cats) or elevation (15 cats) of MABP. MABP was lowered by means of arterial bleeding reducing the blood volume by $3.0-34.4 \mathrm{ml} / \mathrm{kg}$. The blood was collected into heparinised and warmed syringes and reinfused after measurement of $C B F$ at a desired level of MABP had been completed. Elevation of MABP was achieved by constant intravenous infusion of metaraminol bitartrate (Sharp and Dohme) at the rates varying between 0.31 and $2.08 \mathrm{mg} / \mathrm{kg} / \mathrm{h}$. CBF measurements under conditions of normal blood pressure were started one hour after completion of the surgical procedure. In each experiment MABP was either reduced or elevated 2 or 3 times and CBF measured 15 minutes after the new steady level of MABP had been achieved.

In the second group of animals autoregulation of CBF was examined under conditions of hyperammonaemia. The experiments were designed as in the normal blood ammonia group. Infusion of ammonium acetate at the same rate as in series II was started 30 minutes after completion of the surgical procedure. The blood sample to determine arterial blood ammonia concentration was taken $\mathbf{4 0}$ minutes after the onset of ammonium acetate infusion. This was followed by CBF measurements under conditions of normotension. Subsequently, the animals were subjected either to gradual reduction ( 4 cats) or gradual elevation ( 5 cats) of MABP. In each experiment $C B F$ was measured 2-4 times, 15 minutes after stabilisation of MABP at a new level.

In both groups of animals all CBF values were corrected for the difference between $\mathrm{PaCO}_{2}$ found during $\mathrm{CBF}$ measurement and the level of $28 \mathrm{~mm} \mathrm{Hg}$ (see series II) and CVR calculated.

\section{Measurements}

CBF was measured by the ${ }^{133} \mathrm{Xe}$ clearance technique according to the method described by Bates et al. ${ }^{7}$ This technique was recently used by others to measure CBF in cats. ${ }^{89}$ A bolus of $0.9 \% \mathrm{NaCl}(80-100 \mu \mathrm{l})$ containing $0.2-0.3 \mathrm{mCi}$ of ${ }^{133} \mathrm{Xe}$ was delivered into the lingual artery. The radioactivity was measured by a gamma-scintillation detector placed over the right parieto-occipital region of the skull and directed at a right angle to the bone. To diminish extracranial contamination lead screening was extensively used. CBF was estimated by the initial slope method ${ }^{10}$ and expressed in $\mathrm{ml} / \mathrm{min} / 100 \mathrm{~g}$. CBF measurements were repeated with intervals of at least $30-40$ minutes to exclude inaccuracies which might have been related to residual radioactivity.

MABP and ICP were measured with pressure transducers (Statham P-23Db). Measurements of arterial pH, $\mathrm{PCO}_{2}$ and $\mathrm{PO}_{2}$ were performed on blood gas analyser (Radiometer AME-1). Arterial blood ammonia concentration was measured by the colorimetric method. ${ }^{11}$

\section{Statistical analysis}

Means of the data obtained in this study are presented with their standard errors (SE). Differences between mean values were tested by the unpaired $t$ test. The data found in series I and IV were analysed using the least squares method to obtain the trinominal regression equations. Multiple correlation coefficients $(R)$ were calculated and their statistical significance evaluated by $F$ test. The data obtained in series II were subjected to the linear regression analysis. In this case correlation coefficients ( $r$ ) were calculated and their statistical significance evaluated by $t$ test.

\section{Results}

\section{Effect of hyperammonaemia on basal cerebral blood} flow and cerebrovascular resistance

Control arterial blood ammonia concentration amounted to $130.5 \pm 10.7 \mu \mathrm{mol} / 1$ (range $91 \cdot 5-204.0$ $\mu \mathrm{mol} / \mathrm{l})$. Intravenous infusion of ammonium acetate produced an elevation of arterial blood ammonia concentration to $257-1085 \mu \mathrm{mol} / 1$ depending on the rate

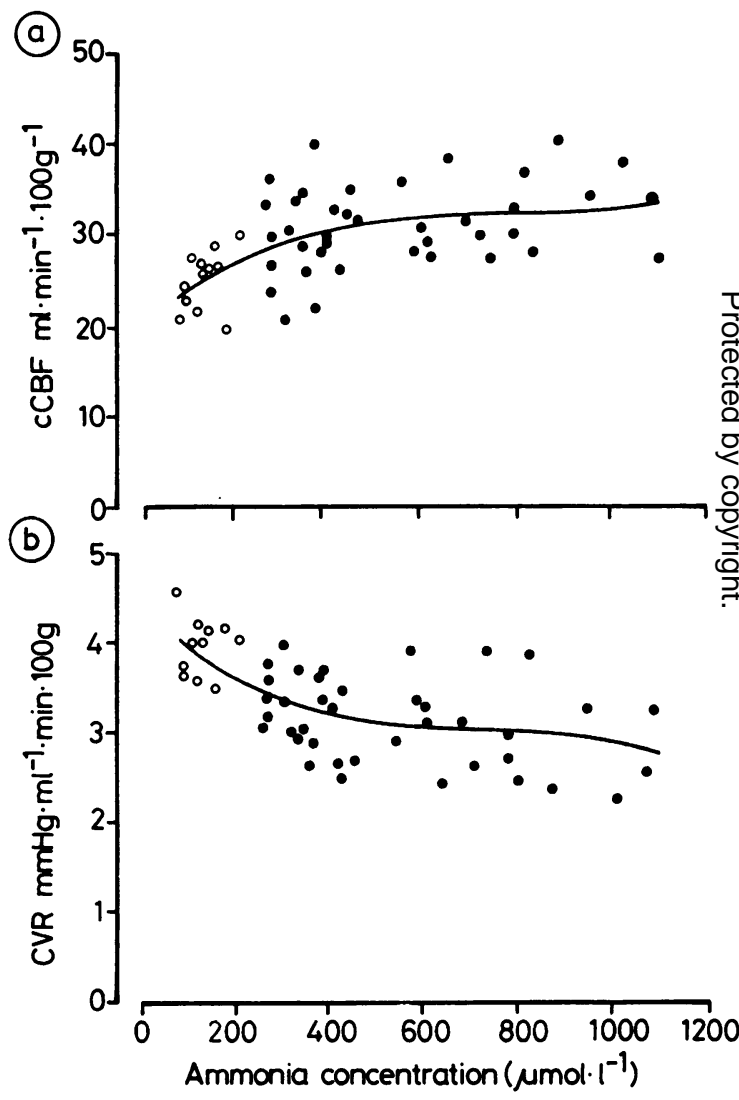

Fig 1 Corrected cerebral blood flow ( $c C B F$, part a) and cerebrovascular resistance ( $C V R$, part b) as a function of arterial blood ammonia concentration. These relationships are described by the following best fit trinominal equations: $a, y=20 \cdot 587+4 \cdot 326 \cdot 10^{-2} x-5 \cdot 383 \cdot 10^{-5} x^{2}+$ $2 \cdot 309 \cdot 10^{-8} x^{3}(n=51, R=0.573, p<0.005) ; b, y=$ $4.448-5.457 \cdot 10^{-3} x+7 \cdot 364 \cdot 10^{-6} x^{2}-3.453 \cdot 10^{-9} x^{3}(n$ $=51, R=0.620, p<0.005)$. Open circles: normal ammonaemia, filled circles: hyperammonaemia. 
of infusion. Elevation of blood ammonia concentration caused a gradual increase in CBF and a parallel decrease in CVR (fig 1). However, both parameters reached plateau as blood ammonia level exceeded 500 $\mu \mathrm{mol} / \mathrm{l}$. Mean values of CBF, CVR and MABP under conditions of normal blood ammonia and after elevation of blood ammonia concentration to above $500 \mu \mathrm{mol} / 1$ are presented in the table.

\section{Effect of hyperammonaemia on cerebrovascular reactivity to $\mathrm{CO}_{2}$}

In series I increasing blood ammonia concentration caused a gradual decrease in cerebrovascular reactivity to $\mathrm{CO}_{2}$ (fig 2) and at arterial blood ammonia level exceeding $500 \mu \mathrm{mol} / 1$ responsiveness of CBF to $\mathrm{CO}_{2}$ was markedly reduced. Under conditions of normal blood ammonia levels mean value of index of chemical CBF regulation was $1.24 \pm 0.07$ $\mathrm{ml} / \mathrm{min} / 100 \mathrm{~g} / \mathrm{mm} \mathrm{Hg}$, whereas after elevation of blood ammonia concentration to above $500 \mu \mathrm{mol} / 1$ it fell to $-0.01 \pm 0.06 \mathrm{ml} / \mathrm{min} / 100 \mathrm{~g} / \mathrm{mm} \mathrm{Hg}$. The change was statistically significant $(p<0.001)$.

Figure 3 shows the relationship between $\mathrm{PaCO}_{2}$ and CBF obtained in series II under normal conditions and with hyperammonaemia. Within normal blood ammonia levels, at arterial blood ammonia level of $132.9 \pm 11.5 \mu \mathrm{mol} / 1$, the slope coefficient of the regression line describing $\mathrm{PaCO}_{2}-\mathrm{CBF}$ relationship was $1.12 \mathrm{ml} / \mathrm{min} / 100 \mathrm{~g} / \mathrm{mm} \mathrm{Hg}(\mathrm{n}=41$, $r=0.863, p<0.001$ ). After elevation of arterial blood ammonia concentration to $805.8 \pm 37.9 \mu \mathrm{mol} / 1$ the slope coefficient of the regression line decreased about 10 times and amounted to 0.11 $\mathrm{ml} / \mathrm{min} / 100 \mathrm{~g} / \mathrm{mm} \mathrm{Hg}(\mathrm{n}=47, \mathrm{r}=0.173, \mathrm{p}>0.05)$. Thus, these results together with those obtained in series I indicate that the cerebrovascular reactivity to $\mathrm{CO}_{2}$ is virtually abolished at arterial blood ammonia level exceeding $500 \mu \mathrm{mol} / 1$.

Similarly as in series I, hyperammonaemia was not accompanied by any significant changes in MABP, which amounted to $101 \cdot 2 \pm 2 \cdot 2 \mathrm{~mm} \mathrm{Hg}$ and $106 \cdot 0 \pm$

Table Basal cerebral blood flow (cCBF), cerebrovascular resistance (CVR) and mean arterial blood pressure ( $M A B P$ ) found in series I under conditions of normal ammonaemia and after elevation of arterial blood ammonia level to above $500 \mu \mathrm{mol} / \mathrm{l}$

\begin{tabular}{lcc}
\hline Parameter & $\begin{array}{l}\text { Normal ammonaemia } \\
(n=12)\end{array}$ & $\begin{array}{l}\text { Hyperammonaemia } \\
(n=18)\end{array}$ \\
\hline cCBF $(\mathrm{ml} / \mathrm{min} / 100 \mathrm{~g})$ & $25 \cdot 1 \pm 0.9$ & $32.4 \pm 1.0^{*}$ \\
CVR $(\mathrm{mm} \mathrm{Hg} / \mathrm{ml} /$ & $3.94 \pm 0.09$ & $3.05 \pm 0.13^{*}$ \\
$\min / 100 \mathrm{~g})$ & $103.1 \pm 3.8$ & $104.4 \pm 2.3$ \\
\hline MABP $(\mathrm{mm} \mathrm{Hg})$ & & \\
\hline
\end{tabular}

${ }^{*} \mathrm{p}<0.001$.

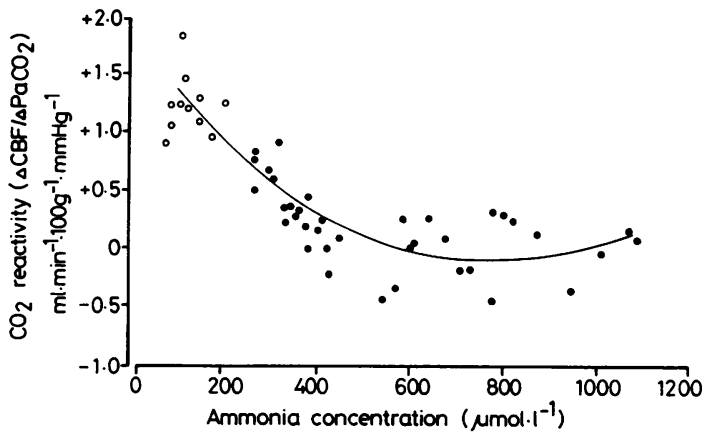

Fig 2 Cerebrovascular $\mathrm{CO}_{2}$ reactivity expressed by the index of chemical $\mathrm{CBF}$ regulation $\left(\triangle \mathrm{CBF} / \triangle \mathrm{PaCO} \mathrm{O}_{2}\right)$ in relation to arterial blood ammonia concentration. The following best fit trinominal equation describes this relationship:

$y=1.923-5 \cdot 873 \cdot 10^{-3} x+5 \cdot 001 \cdot 10^{-6} x^{2}-$ $1 \cdot 018.10^{-9} x^{3}$

( $n=51, R=0.866, p<0.005)$. Open circles: normal ammonaemia, filled circles: hyperammonaemia.
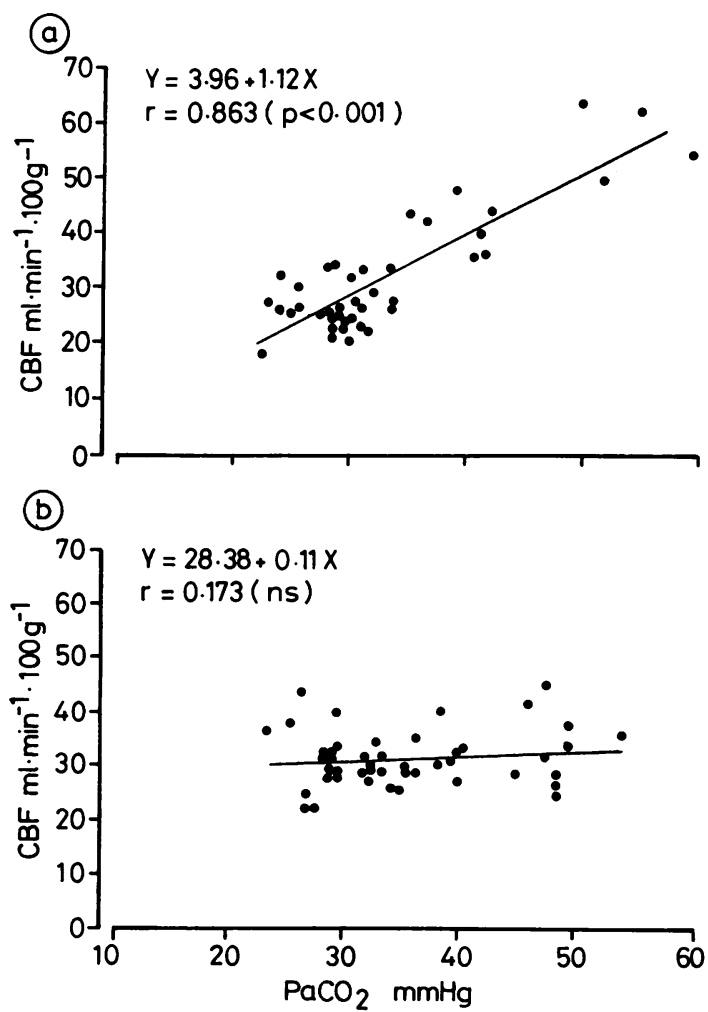

Fig 3 Cerebral blood flow (CBF) as a function of $\mathrm{PaCO}_{2}$ under conditions of normoammonaemia (a) and after elevation of arterial blood ammonia level to above 500 umol/l (b). ns-not significant ( $p>0.05$ ). 
$2.5 \mathrm{~mm} \mathrm{Hg}$ under conditions of normal and raised blood ammonia levels, respectively.

\section{Effect of hyperammonaemia on cerebrovascular reactivity to papaverine}

Mean control arterial blood ammonia concentration in this series of experiments was $129.5 \pm 11.6 \mu \mathrm{mol} / 1$. Cerebrovascular responsiveness to papaverine was evaluated under conditions of normal ammonia levels and after elevation of arterial blood ammonia concentration to $812.3 \pm 69.0 \mu \mathrm{mol} / \mathrm{l}$. Hyperammonaemia did not influence MABP, which amounted to $96.9 \pm$ $3.3 \mathrm{~mm} \mathrm{Hg}$ and $101.2 \pm 3.3 \mathrm{~mm} \mathrm{Hg}$ under conditions of normal and raised blood ammonia levels, respectively. Infusion of papaverine caused only a transient drop in MABP by $10-20 \mathrm{~mm} \mathrm{Hg}$, lasting 2.5-3.5 minutes.

Hyperammonaemia did not change the cerebrovascular reactivity to papaverine. CBF increased after administration of papaverine by $29.9 \pm 3.9 \%$ and $29.2 \pm 3.5 \%$ with normal and raised blood ammonia levels, respectively.

\section{Effect of hyperammonaemia on autoregulation of cerebral blood flow}

Under conditions with normal ammonia levels autoregulatory properties of $\mathrm{CBF}$ were evaluated within the CPP range of $32-183 \mathrm{~mm} \mathrm{Hg}$ at arterial blood ammonia level of $108.1 \pm 5.8 \mu \mathrm{mol} / \mathrm{l}$. The relationship between CPP and CBF demonstrated a typical autoregulatory plateau and CVR was almost linearly related to CPP within the range of CPP between 40 and $120 \mathrm{~mm} \mathrm{Hg}$ (fig 4).

Under conditions of hyperammonaemia autoregulatory properties of $\mathrm{CBF}$ were evaluated within the range of CPP between 43 and $182 \mathrm{~mm} \mathrm{Hg}$ at arterial blood ammonia level of $802 \cdot 2 \pm 46 \cdot 2 \mu \mathrm{mol} / \mathrm{l}$. Within the range of CPP between 60 and $135 \mathrm{~mm} \mathrm{Hg}$ $\mathrm{CBF}$ was relatively constant and CVR almost linearly related to CPP (fig 4). Therefore, these results indicate that the autoregulatory properties of cerebral circulation are preserved when blood ammonia concentration is elevated to a level sufficient to abolish the cerebrovascular reactivity to $\mathrm{CO}_{2}$.

Comparison of the pressure-flow and pressureresistance curves under conditions of normal and raised blood ammonia levels revealed that within the range of CPP between 60 and $120 \mathrm{~mm} \mathrm{Hg}$, in which autoregulation of CBF could be demonstrated in both experimental situations, hyperammonaemia led to displacement of CPP-CBF curve upwards, whereas CPP-CVR curve was displaced downwards. Within this range of CPP mean values of CBF under normal conditions and with hyperammonaemia amounted to $26.8 \pm 0.9 \mathrm{ml} / \mathrm{min} / 100 \mathrm{~g}$ and $32.1 \pm 1.3 \mathrm{ml} / \mathrm{min} / 100 \mathrm{~g}$, respectively. The corresponding mean values of CVR were $3.50 \pm 0.15 \mathrm{~mm} \mathrm{Hg} / \mathrm{ml} / \mathrm{min} / 100 \mathrm{~g}$ and $2.92 \pm$ $0 \cdot 16 \mathrm{~mm} \mathrm{Hg} / \mathrm{ml} / \mathrm{min} / 100 \mathrm{~g}$. Both changes were statistically significant $(p<0.01)$. Thus, these findings

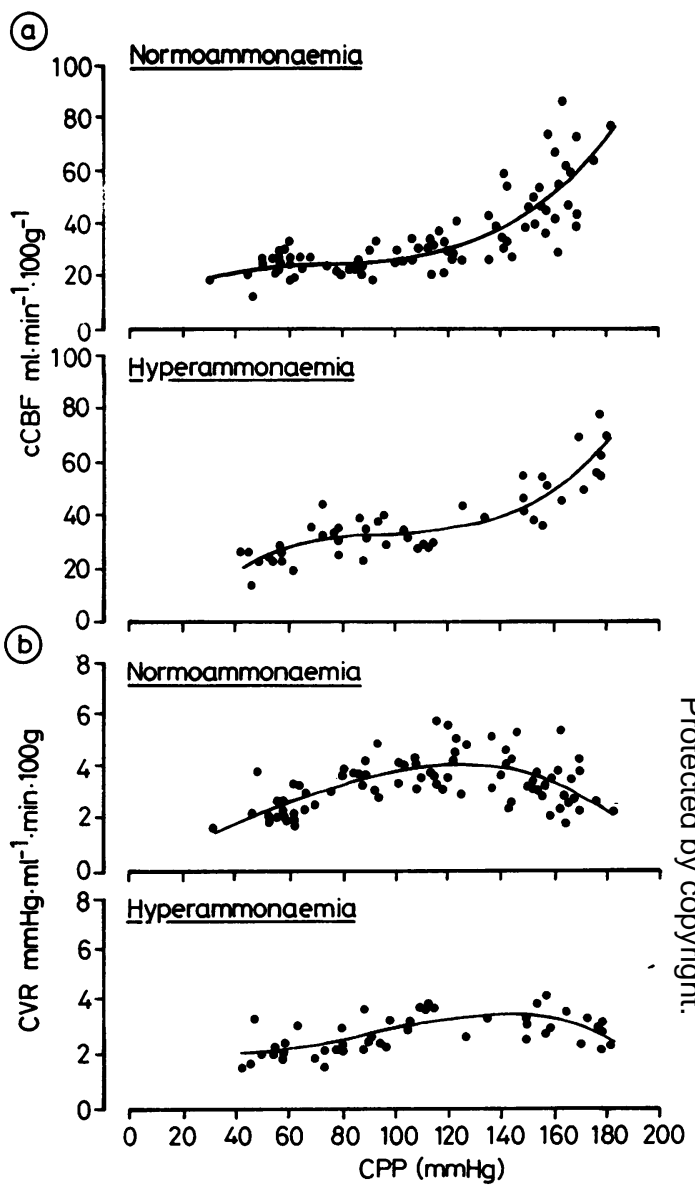

Fig 4 Relationships between cerebral perfusion pressure $(C P P)$ and corrected cerebral blood flow (cCBF, part a) and cerebrovascular resistance (CVR, part b) under conditions of normal ammonaemia and hyperammonaemia (arterial blood ammonia concentration exceeding 500 $\mu \mathrm{mol} / \mathrm{l})$. The following best fit trinominal equations describe above relationships: $C P P-c C B F$ curve in normal ammonaemia, $y=6.358+0.650 x-7.989 \cdot 10^{-3} x^{2}+$ $3 \cdot 539 \cdot 10^{-5} x^{3}$

( $n=85, R=0.834, p<0.005$ ) and $C P P-c C B F$ curve in hyperammonaemia, $y=-22 \cdot 314+1.540 x-$ $1 \cdot 479 \cdot 10^{-2} x^{2}+4 \cdot 957 \cdot 10^{-5} x^{3}$

( $n=47, R=0.886, p<0.005) ; C P P-C V R$ curve in normal ammonaemia, $y=0 \cdot 241+3 \cdot 526 \cdot 10^{-2} x+$ $1 \cdot 648 \cdot 10^{-4} x^{2}-1 \cdot 632 \cdot 10^{-6} x^{3}$

( $n=85, R=0.653, p<0.005)$ and CPP-CVR curve in hyperammonaemia, $y=3 \cdot 178-5 \cdot 307 \cdot 10^{-2} x+$ $8 \cdot 173 \cdot 10^{-4} x^{2}-2 \cdot 972 \cdot 10^{-6} x^{3}$ $(n=47, R=0.674, p<0.005)$. 
confirmed the results obtained in series I that hyperammonaemia causes cerebrovascular dilatation.

\section{Discussion}

\section{Basal cerebral blood flow and cerebrovascular resistance}

Values of basal cerebral blood flow found in the present study under conditions of normal ammonia levels are lower than those obtained in cats by others $^{7-9}$ using the same method of CBF measurement. CBF is known to be influenced in different ways by various anaesthetics. In the present study administration of pentobarbital for induction of anaesthesia and its maintenance with chloralose could in part account for low CBF values obtained. The other reason could be a relatively low level of $\mathrm{PaCO}_{2}$ kept during the experiments. According to the data obtained by Fink and Schoolman ${ }^{5} \mathrm{PaCO}_{2}$ of 28 $\mathrm{mm} \mathrm{Hg}$ was considered in the present study to be a normocapnic level in cats, whereas in the other studies it was usually maintained at $40 \mathrm{~mm} \mathrm{Hg}$. Using the $\mathrm{PaCO}_{2}-\mathrm{CBF}$ relationship with normal ammonia levels, presented in fig $3 \mathrm{a}$, it can be calculated, that in the present study at $\mathrm{PaCO}_{2}$ of $40 \mathrm{~mm} \mathrm{Hg}$ basal CBF would be about $41 \mathrm{ml} / \mathrm{min} / 100 \mathrm{~g}$, that is it would not differ from values of CBF found by others ${ }^{78}$ (39-49 $\mathrm{ml} / \mathrm{min} / 100 \mathrm{~g}$ ) in cats anaesthetised with pentobarbital.

Elevation of blood ammonia concentration has been found in this study to cause a progressive increase in the cerebral blood flow accompanied by a progressive decrease in cerebrovascular resistance. Both parameters stabilised, however, at a relatively constant level as arterial blood ammonia concentration exceeded $500 \mu \mathrm{mol} / \mathrm{l}$. Mean increase in CBF at a plateau level amounted to $29 \%$ and was associated with a decrease in CVR amounting to $23 \%$ of the mean normal ammonia level value.

These results are in agreement with the data reported by Altenau and $\mathrm{Kindt}^{4}$ who found an increase in CBF in ammonia intoxicated rhesus monkeys. Similarly, Gronczewski and Leniger-Follert ${ }^{12}$ have found that intracarotid infusion of ammonium acetate in cats produces an increase in local cerebral microflow. On the other hand, James et al ${ }^{13}$ have found that hyperammonaemia decreases CBF and cerebral metabolic rate of oxygen $\left(\mathrm{CMRO}_{2}\right)$ in dogs. Apart from species differences, the contradictory results obtained in our study and in the study of James et al may be possibly explained by differences in the experimental design. In the latter investigation CBF was determined after a short lasting (10 minutes) infusion of ammonium acetate, whereas in our experiments it was measured not earlier than $\mathbf{4 0}$ minutes after the onset of ammonium acetate infusion. It is worthwhile noting that a transient initial decrease in cerebral microflow has been observed in some experiments of Gronczewski and Leniger-Follert ${ }^{12}$ during intracarotid infusion of ammonium acetate. Thus, it may be possible that $\mathrm{CBF}$ decrease, observed by James et al, ${ }^{13}$ is a transient phenomenon followed by its rise during longer lasting hyperammonaemia.

The present results do not explain the mechanisms of the vasodilatatory effect of ammonia on the cerebral vascular bed. Gronczewski and Leniger-Follert ${ }^{12}$ have suggested that the increase in local microflow, observed by them after intracarotid administration of ammonium acetate, might have been related to the coexisting elevation of extracellular potassium ions activity. These authors have also observed a decrease in extraceilular $\mathrm{pH}$ following changes in $\mathrm{K}^{+}$concentration, which could augment cerebral vasodilatory response to hyperammonaemia.

\section{Cerebrovascular reactivity to carbon dioxide}

The present results demonstrate that elevation of blood ammonia concentration is followed by a progressive decrease in the cerebrovascular reactivity to $\mathrm{CO}_{2}$ and at arterial blood ammonia level exceeding $500 \mu \mathrm{mol} / 1$ responsiveness of $\mathrm{CBF}$ to $\mathrm{CO}_{2}$ is virtually abolished. These data are in accordance with those obtained by Altenau and $\mathrm{Kindt}^{4}$ who found an impairment of the cerebrovascular reactivity to $\mathrm{CO}_{2}$ in rhesus monkeys at arterial blood ammonia level exceeding $540 \mu \mathrm{mol} / \mathrm{l}$. Also, the data obtained by Posner and Plum ${ }^{14}$ suggest that cerebrovascular reactivity to $\mathrm{CO}_{2}$ tends to lower in patients with hepatic encephalopathy.

The mechanism whereby hyperammonaemia reduces the cerebrovascular reactivity to $\mathrm{CO}_{2}$ is not clear. It is known that the responsiveness of CBF to $\mathrm{CO}_{2}$ is influenced by the cerebral oxygen consumption. ${ }^{615} \mathrm{~A}$ decrease in $\mathrm{CMRO}_{2}$ during short lasting hyperammonaemia has been reported by James et al. ${ }^{13}$

The effect of $\mathrm{CO}_{2}$ on $\mathrm{CBF}$ seems to depend not only on its direct action on brain vessels but also on a central neurogenic mechanism localised in the brainstem. ${ }^{15-17}$ With regard to this idea it is worth noting that ammonia intoxication was found to diminish high energy stores in the brainstem of the rat ${ }^{18}$ and specifically in the reticular activating system of the mice brain. ${ }^{19}$ It is, therefore, possible that changes in metabolism of the brainstem may interfere with the neurogenic mechanism controlling CBF response to $\mathrm{CO}_{2}$. As is discussed below the loss of the cerebrovascular responsiveness to $\mathrm{CO}_{2}$ under conditions of hyperammonaemia cannot be explained by the cerebrovascular paralysis, as it was previously suggested by Altenau and Kindt. ${ }^{4}$ 
Cerebrovascular reactivity to papaverine

Mechanism of the vasodilatatory action of papaverine on cerebral vessels is essentially different from that of $\mathrm{CO}_{2}$. Papaverine is known as a very potent inhibitor of phosphodiesterase and causes elevation of intracellular level of cyclic AMP, which in turn stimulates an uptake of calcium ions into their storage sites. ${ }^{2021}$ Takayanagi et al $^{22}$ have found that papaverine not only stimulates $\mathrm{Ca}^{++}$uptake into the microsomal fractions but also inhibits $\mathrm{Ca}^{++}$release from $\mathrm{Ca}^{++}$ stores bound to these fractions. Accordingly, papaverine would cause vasodilatation by interference with intracellular concentration of free calcium.

Elevation of arterial blood ammonia concentration to above $500 \mu \mathrm{mol} / 1$, that is to a level at which the cerebrovascular responsiveness to $\mathrm{CO}_{2}$ is severely impaired, did not cause any significant change in the cerebrovascular reactivity to papaverine. Administration of papaverine elicited almost identical increases in CBF under conditions of normo- and hyperammonaemia. These results indicate, therefore, that abolishment of the responsiveness of $\mathrm{CBF}$ to $\mathrm{CO}_{2}$ at arterial blood ammonia level exceeding $500 \mu \mathrm{mol} / 1$ is not related to the generalised impairment of the cerebral vasomotor activity under conditions of hyperammonaemia.

\section{Autoregulation of cerebral blood flow}

The present results demonstrate that elevation of arterial blood ammonia concentration to a level exceeding $500 \mu \mathrm{mol} / 1$ does not impair autoregulatory properties of the cerebral circulation. Under conditions of normal blood ammonia levels ammonaemia CBF was maintained at a relatively stable level within the CPP range of $40-120 \mathrm{~mm} \mathrm{Hg}$. Under conditions of hyperammonaemia the autoregulatory curve was slightly displaced upwards and to the right; however, a relatively stable level of CBF could be demonstrated within the wide range of CPP changes, that is between 60 and $135 \mathrm{~mm} \mathrm{Hg}$.

The limits of autoregulation of the cerebral blood flow reported in the literature differ, depending on the species examined and on the experimental conditions. ${ }^{23-28}$ In cat, it has been found that the lower and upper limits of CBF autoregulation (regarding values of MABP) are $60 \mathrm{~mm} \mathrm{Hg}$ and $160 \mathrm{~mm} \mathrm{Hg}$, respectively. ${ }^{2930}$ In comparison with the above data the autoregulatory curve obtained by us under conditions of normal blood ammonia levels appears to be shifted to the left. However, it should be emphasised that the limits of autoregulation significantly depend on the level of $\mathrm{PaCO}_{2} .{ }^{233132}$ In our study the pressure-flow relationship with normal blood ammonia levels and hyperammonaemia was examined at a relatively low $\mathrm{PaCO}_{2}$ level, whereas in the other studies performed on anaesthetised cats it has been assumed that the normocapnic $\mathrm{PaCO}_{2}$ level corresponds to $32 \mathrm{~mm} \mathrm{Hg}^{2930}$ or even $40 \mathrm{~mm} \mathrm{Hg}{ }^{78} \frac{}{\mathrm{Z}}$ Recently we have found that autoregulation of CBF $\stackrel{\mathbb{D}}{C}$ in cats subjected to the same anaesthesia as in the present study is maintained within the range of CPP between 70 and $140 \mathrm{~mm} \mathrm{Hg}$ when $\mathrm{PaCO}_{2}$ is estab- 6 lished at a level of $35 \mathrm{~mm} \mathrm{Hg}$ (unpublished observations). These limits of autoregulation fit the results obtained in cats by others. ${ }^{2930}$

Hyperammonaemia is considered to be one of the factors involved in pathogenesis of hepatic encephalopathy. It has been suggested that the deleterious $\stackrel{\vec{S}}{\rightarrow}$ effect of ammonia may be related to impairment of the 0 control of cerebral blood flow. Altenau and Kindt ${ }^{4}$ 듬 have reported that elevation of arterial blood ammo- $\frac{\bar{\rho}}{\sigma}$. nia concentration to a level exceeding $540 \mu \mathrm{mol} / 1 \stackrel{\mathbb{\Omega}}{\Omega}$ results in increase in CBF with loss of the cerebrovascular reactivity to $\mathrm{CO}_{2}$ and impairment of ${ }^{\circ}$ autoregulation of the cerebral circulation. Their con- $\vec{\circ}$ clusion was that ammonia intoxication produces $\overrightarrow{\vec{\omega}}$ paralysis of the cerebral vessels. Unfortunately, the $\stackrel{\sigma}{\omega}$ results supporting this conclusion were reported only in an abstract form without a detailed description of $\frac{}{0}$ experimental procedure and presentation of numer- $\vec{b}$ ical data. Therefore, we decided to reinvestigate the $\omega$ effect of ammonia intoxication on cerebral blood flo $\omega$ and its regulation.

Our results confirm the findings of Altenau and 을 Kindt that hyperammonaemia increases CBF and interferes with cerebrovascular reactivity to $\mathrm{CO}_{2}$. The present study revealed, however, that $\mathrm{CBg}$ responsiveness to directly acting vasoactive agents such as papaverine, is preserved under conditions $\vec{f}$ hyperammonaemia. Furthermore, in contrast to the latter authors, we were unable to prove that hyperammonaemia impairs autoregulation of CBF. Accordingly, our results do not support the hypothesis that ammonia intoxication brings about cerebral vasomotor paralysis.

We thank Dr HD Braun from Sharp and Dohme for the gift of metaraminol bitartrate. We also thank $\mathrm{Dr}$ E Szczepańska-Sadowska for the helpful comments and suggestions on the manuscript and Mrs E Matysiak for the excellent technical assistance. This work was financially supported by the project 10.4.01.12. of the Polish Academy of Sciences.

\section{References}

${ }^{1}$ Hahn M, Massen O, Nencki M, Pawlow J. Die Eck'sche Fistel zwischen der unteren Hohlvene und der Pfortader und ihre Folgen für den Organismus. Arch Exp Pathol Pharmakol 1893:32:161-210.

${ }^{2}$ Chandler WF, Kindt GW. Monitoring and control of $\mathrm{N}$ intracranial pressure in non-traumatic encephalopathies. Surg Neurol 1976:5:311-4. 
${ }^{3}$ Altenau LL, Kindt GW, Chandler WF. Effect of elevated serum ammonia on intracranial pressure. Surg Forum 1976:27:490-1.

${ }^{4}$ Altenau LL, Kindt GW. Cerebral vasomotor paralysis produced by ammonia intoxication. In: Ingvar $\mathrm{DH}$, Lassen NA, eds. Cerebral Function, Metabolism and Circulation. Copenhagen: Munksgaard 1977;346-7.

${ }^{5}$ Fink BR, Schoolman M. Arterial blood acid-base balance in unrestrained waking cats. Fed Proc 1962:21:440.

${ }^{6}$ Fujishima M, Scheinberg P, Busto R, Reinmuth OM. The relation between cerebral oxygen consumption and cerebral vascular reactivity to carbon dioxide. Stroke 1971:2:251-7.

${ }^{7}$ Bates D, Chir B, Sundt TM Jr. The relevance of peripheral baroreceptors and chemoreceptors to regulation of cerebral blood flow in the cat. Circ Res 1976:38:488-93.

${ }^{8}$ Cilluffo JM, Anderson RE, Michenfelder JD, Sundt TM Jr. Cerebral blood flow, brain pH, and oxidative metabolism in the cat during severe insulin-induced hypoglycemia. J Cereb Blood Flow Metab 1982:2:337-46.

${ }^{9}$ Todd MM, Drummond JC. A comparison of the cerebrovascular and metabolic effects of halothane and isoflurane in the cat. Anesthesiology 1984:60:276-82.

${ }^{10}$ Olesen J, Paulson OB, Lassen NA. Regional cerebral blood flow in man determined by the initial slope of the clearance of intra-arterially injected ${ }^{133} \mathrm{Xe}$. Stroke 1971:2:519-40.

${ }^{11} \mathrm{McCullough} \mathrm{H}$. The determination of ammonia in whole blood by a direct colorimetric method. Clin Chim Acta 1967:17:297-304.

${ }^{12}$ Gronczewski J, Leniger-Follert E. Relationship between microflow, local tissue $\mathrm{PO}_{2}$ and extracellular activities of potassium and hydrogen ions in the cat brain during intraarterial infusion of ammonium acetate. In: Lübbers DW, Acker H, Leniger-Follert E, Goldstick TK, eds. Advances in Experimental Medicine and Biology, Vol 169. New York: Plenum Press 1984;291-6.

13 James IM, Garassini M, Larbi E. The effect of ammonium salts on cerebral and hind-limb consumption of oxygen and glucose in the ventilated dog. Clin Sci 1971:41:403-8.

${ }^{14}$ Posner JB, Plum F. The toxic effects of carbon dioxide and acetazolamide in hepatic encephalopathy. $J$ Clin Invest 1960:39:1246-58.

${ }^{15}$ Shalit MN, Reinmuth OM, Shimojyo S, Scheinberg P. Carbon dioxide and cerebral circulatory control. III. The effects of brain stem lesions. Arch Neurol 1967:17:342-53.

${ }^{16}$ Bates D, Weinshilboum RM, Campbell RJ, Sundt TM Jr. The effect of lesions in the locus coeruleus on the physiological responses of the cerebral blood vessels in cats. Brain Res 1977:136:431-43.

${ }^{17}$ Scremin OU, Rubinstein EH, Sonnenschein RR. Cerebrovascular $\mathrm{CO}_{2}$ reactivity: role of a cholinergic mechanism modulated by anesthesia. Stroke 1978:9:160-5.
${ }^{18}$ Schenker S, McCandless DW, Brophy E, Lewis MS. Studies on the intracerebral toxicity of ammonia. J Clin Invest 1967:46:838-48.

${ }^{19}$ McCandless DW, Schenker S. Effect of acute ammonia intoxication on energy stores in the cerebral reticular activating system. Exp Brain Res 1981:44:325-30.

${ }^{20}$ Andersson RGG. Cyclic AMP and calcium ions in mechanical and metabolic responses of smooth muscles; influence of some hormones and drugs. Acta Physiol Scand, Suppl 382, 1972;1-59.

${ }^{21}$ Sunagane N, Uruno T, Kubota K. Mechanism of relaxant action of papaverine. Effect on caffeine-induced contraction of guinea pig taenia coli. Jpn J Pharmacol 1982:32:785-93.

${ }^{22}$ Takayanagi I, Hisayama T, Suzuki S. Effects of nonspecific smooth muscle relaxants and $\mathrm{Ca}$-blocker on $\mathrm{Ca}$-release and $\mathrm{Ca}$-binding in microsomal fractions from rabbit taenia coli. Jpn J Pharmacol 1980:30:641-6.

${ }^{23}$ Iwabuchi T, Kutsuzawa T, Ikeda K, Nakamura T. Effects of blood gases on the pressure-flow relationships in canine cerebral circulation. Stroke 1973:4:65-72.

${ }^{24}$ Morita H, Nemoto EM, Bleyaert AL, Stezoski SW. Brain blood flow autoregulation and metabolism during halothane anesthesia in monkeys. Am $J$ Physiol 1977:233:H670-H676.

${ }^{25}$ Olesen J. Quantitative evaluation of normal and pathologic cerebral blood flow regulation to perfusion pressure. Arch Neurol 1973:28:143-9.

${ }^{26}$ Strandgaard S, Olesen J, Skinhøj E, Lassen NA. Autoregulation of brain circulation in severe arterial hypertension. Br Med J 1973:i:507-10.

${ }^{27}$ Strandgaard S, MacKenzie ET, Sengupta D, Rowan JO, Lassen NA, Harper AM. Upper limit of autoregulation of cerebral blood flow in the baboon. Circ Res 1974:34:435-40.

${ }^{28}$ Strandgaard S, MacKenzie ET, Jones JV, Harper AM. Studies on the cerebral circulation of the baboon in acutely induced hypertension. Stroke 1976:7:287-90.

${ }^{29}$ MacKenzie ET, Farrar JK, Fitch W, Graham DI, Gregory PC, Harper AM. Effects of hemorrhagic hypotension on the cerebral circulation. I. Cerebral blood flow and pial arteriolar caliber. Stroke 1979:10:711-8.

${ }^{30}$ MacKenzie ET, Strandgaard S, Graham DI, Jones JV, Harper AM, Farrar JK. Effects of acutely induced hypertension in cats on pial arteriolar caliber, local cerebral blood flow, and the blood-brain barrier. Circ Res 1976:39:33-41.

${ }^{31}$ Raichle ME, Stone HL. Cerebral blood flow autoregulation and graded hypercapnia. Eur Neurol 1971/2:6:1-5.

${ }^{32}$ Paulson OB, Olesen J, Christensen MS. Restoration of autoregulation of cerebral blood flow by hypocapnia. Neurology (Minneap) 1972:22:286-93. 